\title{
GASTRIC MOTILITY AND THE VOLUME OF GASTRIC SECRETION IN MAN
}

By ARTHUR L. BLOOMFIELD AND CHESTER S. KEEFER

(From the Department of Medicine, Stanford University Medical School, and the Johns Hopkins University, Medical Department)

(Received for publication July 18,1927 )

In a previous paper (1) we discussed the relation of degree of gastric acidity of people without organic disease of the stomach to physical fitness, age, and other factors. It was shown that acidity tends to decrease with advancing years and that people in poor general physical condition, on the whole, have a less acid stomach juice than those who are fit. The present report deals with a similar study of the volume of gastric secretion and gastric motility after a standard stimulus.

\section{METHODS}

The subjects were part of the group used for the previous observations (1). As far as possible organic lesions of the stomach were excluded in every case. The tests were carriet out by the method which has previously been described in detail $(1,2)$.

\section{The volume of gastric secretion}

In a previous paper (3) it was pointed out that following stimulation of the stomach with $50 \mathrm{cc}$. of 7 per cent alcohol the maximum tenminute volume of gastric secretion varied in different people from 10 to $40 \mathrm{cc}$. with occasional greater or smaller values. The present larger series of 51 people is in essential agreement since all but four observations fall within the range of 10 to $50 \mathrm{cc}$.

\section{Relation of volume of secretion to age}

In view of the clear relationship of gastric acidity to age, an inquiry was made as to the relation of age to volume of gastric secretion. The dots in chart 1 indicate the highest ten-minute secretion volumes, after the standard alcohol stimulus, in different cases plotted in rela- 
tion to the age of the subjects. The tendency to lower volumes in older people is obvious and is shown graphically in chart 2 . The explanation of this phenomenon is not yet clear.

\section{Relation of volume of secretion to physical fitness}

It was found that gastric acidity was diminished in people whose physical condition was poor. No such clear relationship could be demonstrated in the present series with regard to volume of secretion.

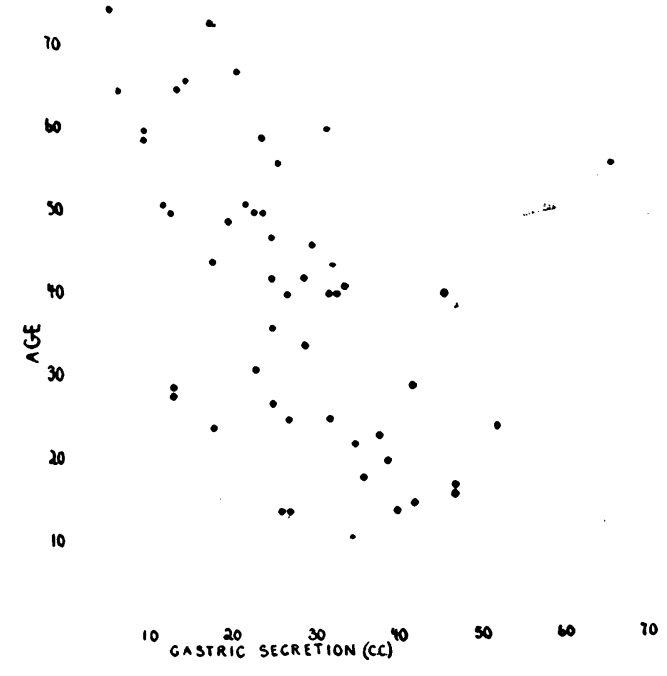

Chart 1

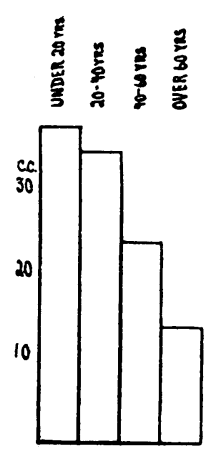

Chart 2

Chart 1. Relatton of Volume of Gastric Secretion to Age

Chart 2. Relation of Volume of Gastric Secretion to Age

The average maximum ten-minute volume of those in good condition was $33.5 \mathrm{cc}$; of those in bad condition $27 \mathrm{cc}$. That these figures were not due to accidental age distribution in the two groups is shown by the following analysis (table 1).

\section{Gastric motility}

The question of gastric motility may be discussed from either of two aspects. First, there are the considerations of pure physiology 
which deal with the complex phenomena of the contractions of the stomach and with the analysis of the neuromuscular mechanisms which are involved. Secondly, there is the clinical problem of the diagnostic significance of gastric motility. Radiologists and clinicians have placed a good deal of stress on "retention" beyond a certain length of time, "spasm," "hypermotility" and "atony," but the exact interpretation of gastric motility in disease, apart from definite pyloric obstruction, is still very uncertain. The present observations have little, if any, theoretical importance; they deal simply with an objective study of the volume of contents and the emptying time of the stomach under controlled conditions after a standard stimulus. Our object was to obtain, if possible, a base line with which the findings in instances of gastric disease could be compared.

TABLE 1

Relation of age and physical condition to volume of gastric secretion

\begin{tabular}{|c|c|c|c|}
\hline & All cases & Good condition & Bad condition \\
\hline & $c c$. & $c c$. & cc. \\
\hline All cases. . . . . . . . . . . . . . & & 33.5 & 27 \\
\hline Under 30 years.............. & 33 & 41.0 & 37 \\
\hline 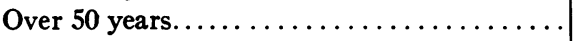 & 20 & 20.0 & 19 \\
\hline
\end{tabular}

The procedure, as previously described, consisted of introducing into the empty stomach through a small tube $50 \mathrm{cc}$. of 7 per cent alcohol. The subjects were all in bed under "basal" conditions. At ten-minute intervals the entire stomach contents were aspirated through the tube, which remained in place throughout the experiment. A sample of $10 \mathrm{cc}$. was retained at each aspiration and the remainder was immediately re-injected into the stomach. It was possible, therefore, to plot curves showing the volume of stomach contents at regular intervals. Such volumes, needless to say, represent the sum of the fluid introduced and the gastric secretions, less contents which have escaped through the pylorus. A few curves were published in a previous paper (3) but a much larger series (consecutive cases) is now presented.

It is at once apparent that the curves (chart 3) have an orderly character; two different types can be distinguished. In the first group, 
following the introduction of the alcohol there is a steady increase in gastric content which reaches a maximum in from 30 to 50 minutes

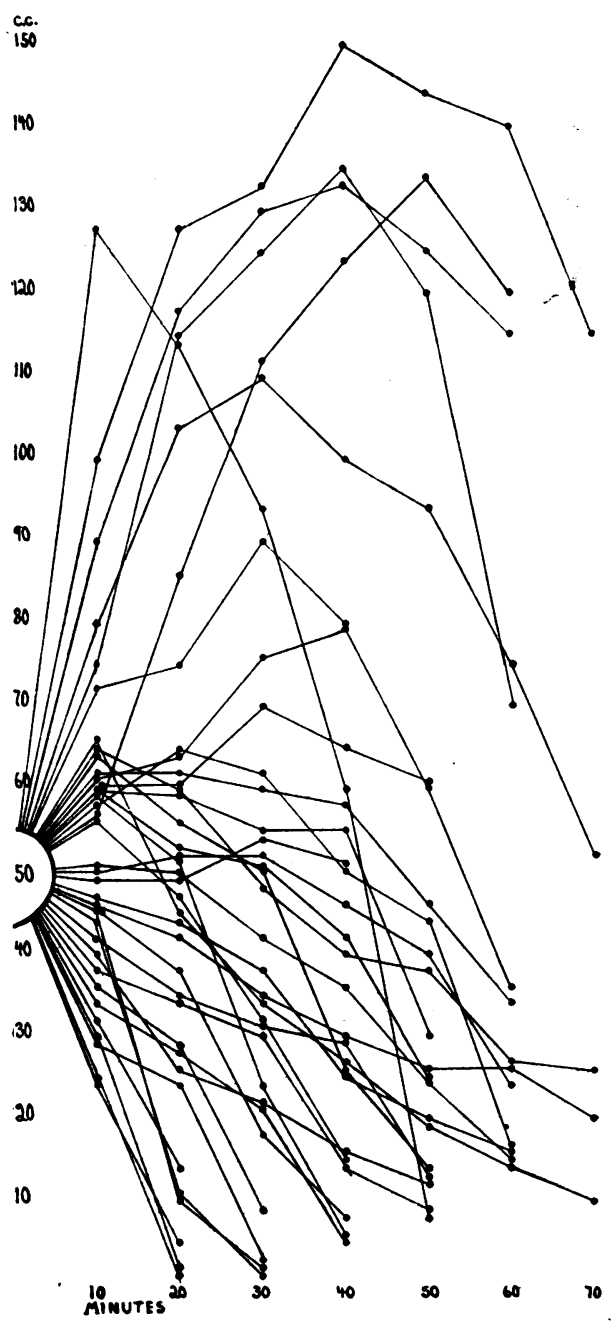

Chart 3. Volume Curves of Gastric Contents

and then declines, often rapidly; in the second group the volumes decrease from the start. In a few cases the curve is intermediate between the other two types. It is of interest that the regularity of 
the curve does not seem to be interfered with by the frequent aspirations; in no instance, for example, does the curve rise after once beginning to fall. It is evident that under the conditions of these experiments a regular and orderly action of the stomach is revealed; the rising curves, of course, indicate predominance of gastric secretion over discharge; the falling curves indicate the reverse, although

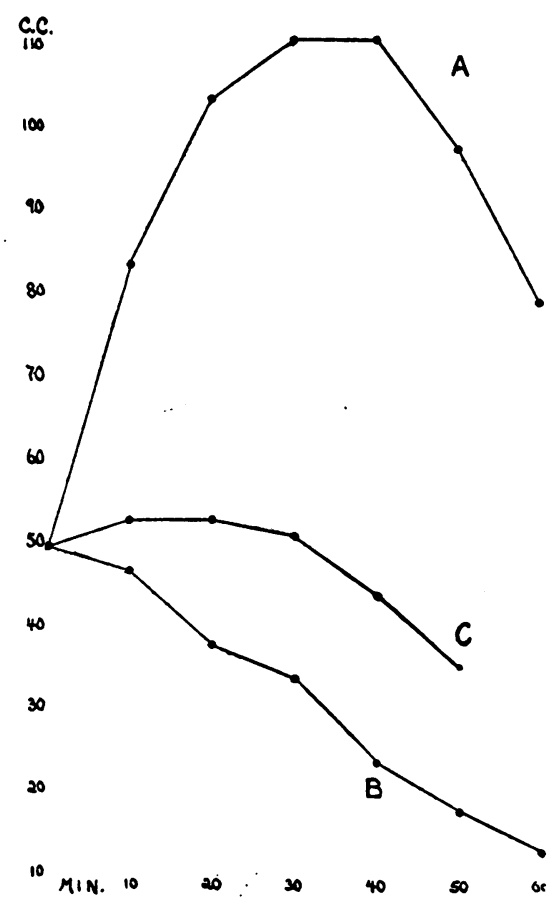

Chart 4. Compostte Volume Curves of Gastric Contents

neither type gives any direct information as to volume of gastric secretion. We have found, however, that the high curves are usually associated with large volumes of secretion; the falling curves may or may not have such significance. Chart $4(\mathrm{C})$ is a composite graph of the averages of all the curves shown in chart 3. $A$ is a composite of all the curves with initial rise and $B$ of all the curves with an initial fall. 


\section{Emptying time of stomach}

Chart 3 also shows the emptying time in various cases. The great variation is apparent; in some cases the stomach.was empty in 20

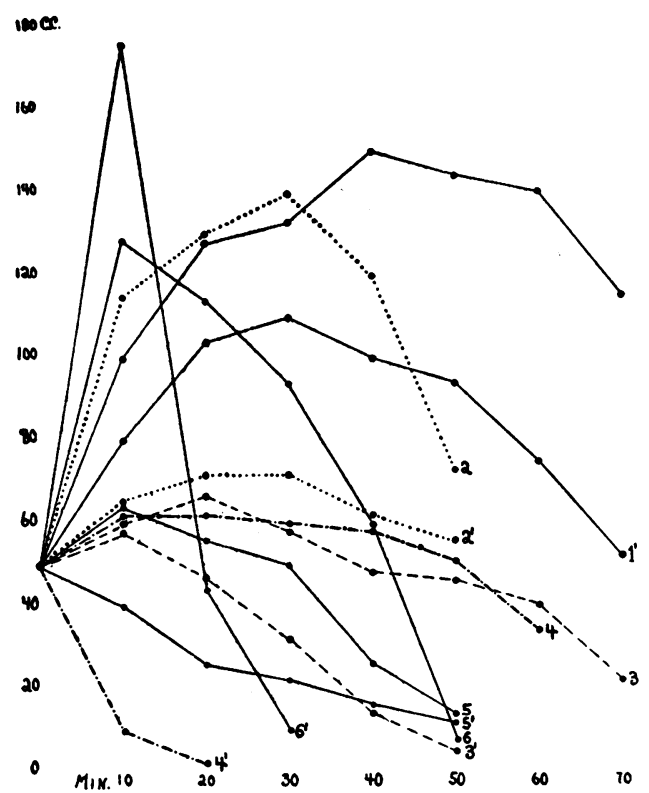

Chart 5. Repeated Volume Curves of Gastric Content

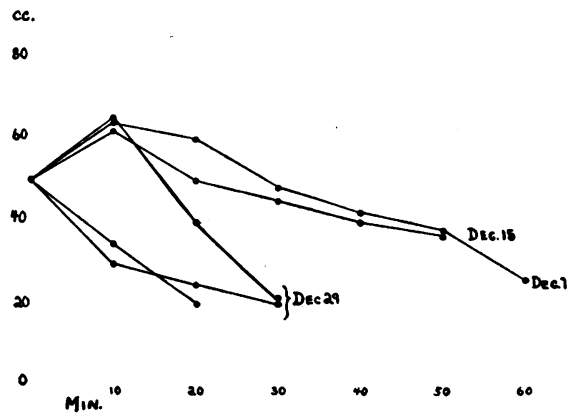

Chart 6. Repeated Volume Curves in One Patent

minutes, in others there was still a large quantity of gastric contents at the end of an hour or more. In view of the orderly character of 
the curves, we tried to find out if the type of curve was characteristic of a particular stomach. Repeated observations were therefore made in a number of cases and the graphs are shown in chart 5. In our previous paper $(3,4)$ we stressed the great variations in the motility of the stomach on successive examinations. While this fact is quite correct there is none the less a striking general similarity between most of the curves obtained on successive occasions in the same subject. Six pairs of curves are shown in chart 5. Each pair represents the first examination and a second one made after an interval of a week or more. Curves 4 and $4^{\prime}$ are the only ones which show any extreme difference. We have repeated observations in 15 cases; in 12 the curves were similar. Chart 6 shows curves from five examinations of the same person. In all a good deal of similarity is apparent although the speed of emptying varies.

\section{SUMMARY}

The present observations have been made with a view to establishing the volume of secretion and the gastric volume curve after a uniform stimulus in order to set standards with which observations in instances of gastric disease can be compared.

In addition to defining the normal variations in volume of gastric secretion it is pointed out that volume of secretion as well as acidity decrease with advancing years. Curves of volume of total gastric content are presented and discussed.

\section{BIBLIOGRAPHY}

1. Bloomfield, A. L., and Keefer, C. S., J. Clin. Invest., 1928, v, 285. Gastric Acidity: Relation to Various Factors such as Age and Physical Fitness.

2. Bloomfield, A. L., and Keefer, C. S., J. Am. Med. Assoc., 1927, lxxxviii, 707. Clinical Studies of Gastric Function.

Bloomfield, A. L., and Keefer, C. S., Arch. Int. Med., 1926, xxxvii, 819. A method for the Continuous Quantitative Estimation of Gastric Secretion and Discharge in Man.

3. Bloomfield, A. L., and Keefer, C. S., Arch. Int. Med., 1926, xxxviii, 145. Clinical Physiology of the Stomach.

4. Keefer, C. S., and Bloomfield, A. L., Am. J. M. Sc., 1927, clxxiii, 460. Observations on Gastric Function in Digestive Disorders. 